\title{
A Longitudinal Study of Retention and Grade Performance of Participants in an Engineering Entrepreneurs Program
}

\author{
Matthew W. Ohland, Clemson University \\ Guili Zhang, University of Florida \\ Catherine E. Brawner, Research Triangle Educational Consultants \\ Thomas K. Miller, III, North Carolina State University
}

\begin{abstract}
The Engineering Entrepreneurs Program at North Carolina State University is a program in which undergraduate students participate in design teams formed around corporate technology start-up company themes. Through funding from the NSF-sponsored SUCCEED (Southeastern Universities and Colleges Coalition for Engineering EDucation) Coalition, the Entrepreneurs Program aims to retain student interest in engineering by exposing undergraduate students to the design process early in their academic careers and by providing upper class students as mentors. Secondly, it seeks to teach students "real-world" skills such as teamwork, leadership, and the dynamics of entrepreneurship.

Multiple approaches to assessment - qualitative means such as surveys and focus groups as well as quantitative methods such as longitudinal assessment of retention and GPA - triangulate on the benefit of the program. The design of program is discussed, so that it may serve as a model program. This model should be of value to anyone who is interested in providing vertically integrated, multidisciplinary, practice-based engineering design experiences.
\end{abstract}

\section{Entrepreneurship and teaching}

Between 1980 and 1988, during which time the Fortune 500 companies lost in excess of 3.5 million jobs, 17 million new employment positions were created by entrepreneurship start-up enterprises. Then, in 1990 alone, 500,000 businesses were founded by self-employed entrepreneurs. ${ }^{1}$ Today, nearly 50 percent of the growth in the US economy can be explained by entrepreneurial activity. ${ }^{2}$ These impressive statistics make a strong case for entrepreneurship as one way to drive economic growth.

Since "real world" economic success requires both technical feasibility and economic viability, an engineering curriculum that integrates both aspects could therefore be of considerable value. ${ }^{3}$ Also, of the over 200,000 graduates of college engineering and science programs each year, a growing proportion are finding employment in small businesses and start-up ventures - the type of environment that requires "a new type of engineer, an entrepreneurial engineer, who needs a broad range of skills and knowledge above and beyond a strong science and engineering background."4 
While developing entrepreneurial skills is certainly valuable, engineering students are rarely exposed to the entrepreneurial perspective at either the undergraduate or graduate level. ${ }^{5,6,7}$ Historically, curricula have been dominated by design-and-build projects with an emphasis on technical excellence that has for the most part excluded the overriding picture of costs, timing and other market forces. Recent conferences are particularly good sources of project-based approaches to meeting these objectives. ${ }^{8,9,10}$ The fundamental question of product marketability is among the least addressed in an engineering classroom. ${ }^{11}$

Championing the need for the development of entrepreneurship in engineering education is the National Collegiate Inventors and Innovators Alliance, an initiative of The Lemelson Foundation. The NCIIA is an alliance of faculty and students working to advance the teaching of invention and innovation in American higher education. Its mission is to nurture a new generation of innovators by promoting curricula designed to teach creativity, invention, and entrepreneurship. ${ }^{12}$

A challenge to engineering entrepreneurship programs is to provide evidence of their success. Kingon and his colleagues point out that there is "relatively little published information regarding the efficacy of entrepreneurial programs or courses, particularly in the newer programs within engineering." 13

\section{The contribution of the NC State Engineering Entrepreneurs Program}

Fueled by the excitement of watching two student entrepreneurs chase and grab hold of their dream of starting a technology company and tempered by his own experience with a small start-up venture, ${ }^{14}$ Tom Miller started the Engineering Entrepreneurs Program (EEP) ${ }^{15}$ at North Carolina State University in 1993. Funding from the National Science Foundation through SUCCEED, the Southern University and College Coalition for Engineering Education, ${ }^{16}$ supported the creation of this program, designed to teach students how to navigate the entrepreneurial process.

The Engineering Entrepreneurs Program (EEP) is a multi-semester experience in which students participate on project teams oriented around a corporate theme. The course seeks to promote some of the skills we desire of engineering graduates by introducing students to the design process early in their academic careers and preparing them for the workplace by exposing them to the dynamics of small, entrepreneurial companies. Students participating in EEP may be at any level (freshman through senior) and from any discipline, although most participants are electrical and computer engineering majors. In this paper, we discuss the goals, organization, operation, and assessment of the program. The lessons learned through the administration of this course are available elsewhere. ${ }^{17}$

While faculty mentorship is still important, the EEP model relies heavily on the leadership role played by seniors who appear to be the most critical factor in the ultimate success or failure of the team. Multi-semester involvement by the students reduces faculty load because senior leaders who have previously been involved as participants in the program require less initial effort to get the team organized and underway. Multi-semester participation has also proved to be beneficial to team performance, based on survey results summarized later. In contrast to the majority of the

Proceedings of the 2003 American Society for Engineering Education Annual Conference \& Exposition Copyright $\left({ }^{\circ} 2003\right.$, American Society for Engineering Education 
literature on entrepreneurship programs in engineering, the Engineering Entrepreneurs Program has been assessed using both qualitative and quantitative methods in addition to strong anecdotal evidence, some of which is summarized here, and some of which is presented here for the first time.

\section{Program Goals}

There are six goals of the EEP that focus on improving the students' educational experience and their ability to function effectively in the workplace.

1. Retain the interest of students in engineering by involving them in meaningful design experiences early in their academic careers.

2. Improve the quality of engineering students by involvement in multi-semester design activities.

3. Improve retention by providing senior leaders as role models for underclassmen.

4. Improve teamwork skills by involving students in team-oriented projects, similar to what they will encounter in the workplace.

5. Improve leadership skills by assigning seniors management responsibilities for the project and team personnel.

6. Prepare students for the 21 st century workplace by exposing them to the dynamics of small, entrepreneurial companies, which are expected to generate most new jobs in the foreseeable future.

These goals follow from two basic principles under the unifying theme of entrepreneurship. First, engineering students should be exposed to the design process early and continuously throughout their academic careers and second, students should be prepared for the working world that awaits most of them upon graduation.

\section{Program Organization}

The EEP builds on the capstone design course that is currently required at the senior level in most engineering curricula, yet is not organized in the same way as a traditional engineering course. Students attend mandatory weekly seminars on business topics and work on their team project outside of class. There are no prerequisites; students at all levels, freshman through senior, can participate.

Students participating in the EEP are classified into two categories: "senior leaders" and "team participants." The senior leaders are earning capstone design course credit by their participation while team participants earn one credit hour for each semester of participation. The senior leaders, in addition to being responsible for the "deliverables" of the design team, are also expected to play a leadership role. It is their responsibility to define the team's mission, organization, goals, and objectives. This contrasts with the traditional student role in a capstone design course where teams of peers work on a project, in that team participants who are not in leadership positions play a supporting role. They are expected to participate at an effort level commensurate with one

Proceedings of the 2003 American Society for Engineering Education Annual Conference \& Exposition

Copyright (C) 2003, American Society for Engineering Education 
hour of credit, and to contribute to the team activities at a technical level consistent with their academic expertise.

Each team has a faculty advisor. The primary role of the faculty advisor is to serve as mentor and facilitator for the team, and to make sure that team organization and role definition takes place. Managing the group dynamics is probably the most important and challenging role for the advisor.

While the EEP does not include a formal lecture, it does include a weekly seminar. The seminars are best if presented by outside speakers, and may be on any topic relevant to the theme of the program (e.g.: teambuilding, developing a business plan, obtaining venture capital, consulting, legal matters, and marketing). Seminar speakers have included attorneys, management consultants, marketing specialists, founders of entrepreneurial companies (successful and unsuccessful), venture capitalists, plant managers, manufacturing engineers, and others. The seminar series has proven to be an important part of the program, providing the students with a viewpoint on engineering and technology in the "real world" that is seldom seen in the classroom.

In addition to the seminars, student presentations are emphasized in the program. Each team presents three times during the semester. At the first presentation, each team presents its corporate philosophy, mission, goals for the semester, and strategy to achieve those goals. By scheduling the first presentation as early as possible in the semester, the teams are forced to organize and develop their goals and strategies quickly. At the second presentation, the team reviews its mission, goals, and strategy; gives a midterm progress report on how well those goals are being achieved, and documents any changes in strategy or organizational structure. The final presentation documents the achievements of the semester. The teams present and demonstrate the prototype technology they have developed and outline their plans for the future of their company and product.

\section{Team Formation and Organization}

Teams are composed of senior leaders and team participants. Team sizes may vary, but teams of 5 to 10 students (including two senior leaders) have worked well. Class members are recruited in a number of ways. Freshmen students are informed about the class through summer mailings and visits by faculty advisors to "Introduction to Engineering" classes. Previous EEP participants also recruit new members to their teams and faculty advisors steer other interested students to the EEP. Senior leaders who have not previously participated in the EEP are recruited from the Senior Design classes. Students are allowed to take the class for multiple semesters, although generally only about $25 \%$ of the participants in a given semester have taken it previously.

Teams are organized around company themes. During the first class meeting, students who have not already been recruited to a team join a company whose theme interests them. Company themes have included portable medical devices, software development, and others. The students and the faculty advisor work together during the start-up phase to define potential customers and a particular product consistent with the company's theme. Some companies also have industry sponsors such as IBM or Nortel. Students typically develop a name and logo to go with the

Proceedings of the 2003 American Society for Engineering Education Annual Conference \& Exposition

Copyright (C) 2003, American Society for Engineering Education 
theme. Hence, the portable medical devices theme became Body Systems Innovations.

During the first team meeting, students begin the process of organizing their team into a business around the corporate theme and begin the process of deciding what their product will be. The teams' organizational structure may vary, but teams are encouraged to assign team members responsibility for leadership (president, CEO), record keeping (secretary), product development and testing, and business development. The senior leaders develop an organizational structure with defined areas of responsibility for each participant. We have found that it is best if each participant has a well-defined responsibility, even if the responsibility is small. This ensures up front that each student feels that he or she is part of the team and minimizes the risk that the seniors will end up working in isolation from the rest of the group just to get the job done. It also forces the seniors to make their first critical leadership decisions.

\section{Team Operation}

The teams are responsible for designing and building a working prototype of a product that is consistent with their company's theme and mission by the end of the semester. Senior leaders are ultimately responsible for the outcome but team members can be valuable contributors if their skills are used well. For instance, one team that was developing prototype software used the freshman students on the team to test the software to ensure that it could be used and understood by people with minimal technical competence. All teams are required to document their work, including design drawings and decisions made that are turned in at the end of the semester with other project documentation.

Senior leaders say they spend at least 12 hours per week on the class and related project work. This is to be expected from a 4 hour class and a capstone design project. Other team members say that they generally spend between two and five hours per week on class activities. The level of effort required of the faculty advisor is initially high (about 4-8 hours per week), but soon decreases to about 1-2 hours per week in the steady state. When a substantial number of the team members, particularly the senior leaders have participated in previous semesters, the start-up burden for the faculty advisor is greatly reduced.

\section{Grading}

The EEP attempts to employ a success-oriented approach to evaluation and grading. There are no tests. Attendance at seminars, student presentations, and weekly team meetings is required. Grading is based on assessment of how well each participant filled the role set out for him/her at the beginning of the semester.

The seniors are additionally judged on their leadership skills and their fulfillment of the requirement that they define a role for all team participants and ensure their involvement in the project. Team participant evaluations of senior leadership effectiveness and senior leader evaluation of participant contributions are also used as factors in grading. These evaluations can alter a student's final grade by one letter grade. Knowing that the leaders and participants are each

Proceedings of the 2003 American Society for Engineering Education Annual Conference \& Exposition Copyright $($ 2003, American Society for Engineering Education 
evaluating the other encourages both groups to make sure that their roles are well defined and well understood by the other. Due to the subjective nature of the grading, it is important for the faculty advisor to attend the weekly team meetings and monitor individual activities, contributions, and problems.

\section{Earlier Studies}

Earlier assessment focused on making recommendations for EEP improvement. A study was performed after the course had been offered for six semesters to determine how well the course was meeting its objectives. Overall, the findings of the evaluation were very positive. Interviews and surveys were conducted with many students who had participated in the program to get their perspective on their experience. In addition, university data were available for over 100 students in the entering classes ("cohorts") of 1990 through 1994 who had taken the course. These students were compared with other NC State University students for their retention at the university and in their majors. End-of-course survey results from 120 students over the six semesters were also used to get a complete picture of how the course was meeting its objectives.

\section{$\underline{\text { Student Profile for Earlier studies }}$}

In the six semesters that the EEP had been offered before the earlier study, 159 students had participated. Of these, 113 or $71.1 \%$ had taken the course one time and $46(28.9 \%)$ had taken the course more than once. Table 1 shows the frequency of course participation.

Table 1. Frequency of Course Participation for Students in Earlier Study

\begin{tabular}{l|c|c|c|c|c|c} 
Number of semesters participated & $\mathbf{1}$ & $\mathbf{2}$ & $\mathbf{3}$ & $\mathbf{4}$ & $\mathbf{5}$ & $\mathbf{6}$ \\
\hline Number of students & 113 & 26 & 15 & 3 & 1 & 1
\end{tabular}

Of the 159 total students, university data was available for 130 of them who had taken the EEP before Fall 1995 and for whom a social security number was available. Four of these students were graduate students and were deleted from further analysis. Of the 126 left, 109 entered the university as freshmen while the rest transferred in later in their careers. Table 2 shows the entering year ("cohort year") for the 126 students.

Table 2. Year of Program Entry for Students in Earlier Study

\begin{tabular}{l|c|c|c|c|c|c} 
Entering year & Before 1990 & $\mathbf{1 9 9 0}$ & $\mathbf{1 9 9 1}$ & $\mathbf{1 9 9 2}$ & $\mathbf{1 9 9 3}$ & $\mathbf{1 9 9 4}$ \\
\hline Number of students & 23 & 16 & 12 & 24 & 21 & 30
\end{tabular}

Of the 126 students, nearly $90 \%$ (113) were men. In contrast, $40 \%$ of the students at NC State were women as were $22 \%$ of the engineers. The students included in the study were overwhelmingly white (107 or $84.9 \%$ ). Asians were the largest minority with $11 \%$ of the students. Only five students (4\%) were Hispanic, African American or American Native. This was not atypical of the general population, however - approximately $82 \%$ of both the student body and the engineering school were white. 
As would be expected, most of the students (117) entered the University in the College of Engineering. The remaining students were either in the College of Physical and Mathematical Sciences (PAMS) (7) or Forestry (2). Table 3 shows the breakdown of students by entering curriculum. Students who were undesignated with a preference (e.g. electrical engineering undesignated) are represented in the ECE department. Students who were simply "Engineering Undesignated" in university records are listed as such.

Table 3. Frequency of Matriculation Discipline for Students in Earlier Study

\begin{tabular}{l|c} 
Matriculation discipline & Number of students \\
\hline Electrical and Computer Engineering & 69 \\
\hline Other Engineering, Specified & 29 \\
\hline Other Engineering, Undesignated & 19 \\
\hline Physical and Mathematical Sciences & 7 \\
\hline Forestry & 2
\end{tabular}

\section{Findings from Earlier studies}

Students who participated in the EEP were found to be more likely to remain at the university (Figure 1) and remain in their college of entry (Figure 2) than non-participants. In both of these charts, the persistence is based on data from October, 1995. Therefore, the second year is represented for the 1994 cohort while the sixth year is represented for the 1990 cohort. The EEP even caused a few students to change their majors to Electrical and Computer Engineering from other disciplines. Some of the younger students surveyed indicated that the EEP was one of the reasons that they decided to remain in their engineering major. Students who take Entrepreneurship were even found to be attracted to the Electrical and Computer Engineering Department from other engineering and science majors. Retention in the University was nearly perfect and retention in the College of Engineering is substantially better than overall persistence in the College. (Persistence is those enrolled plus those who have graduated). 


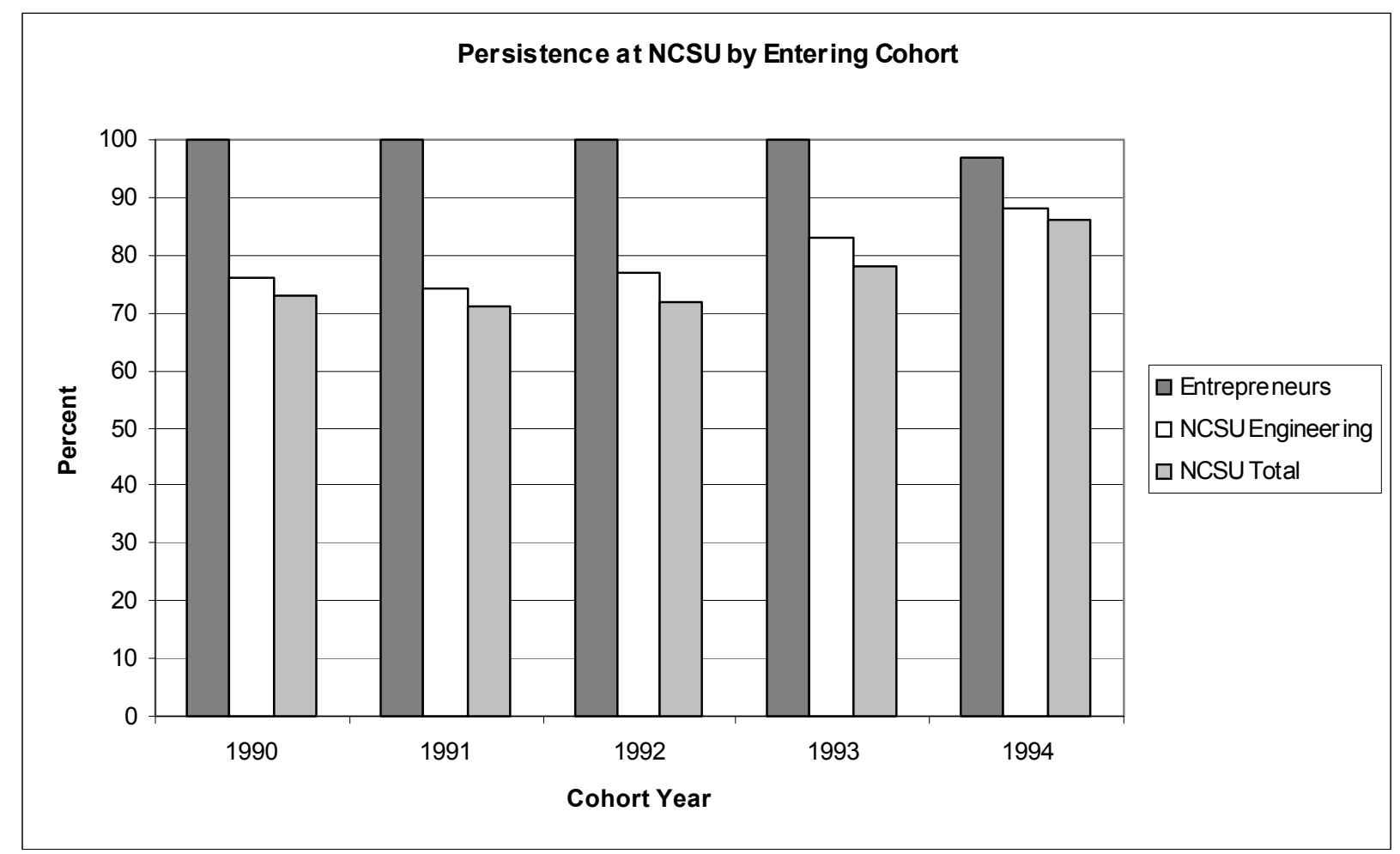

Figure 1. Persistence at NCSU by Entering Cohort (Earlier Study)

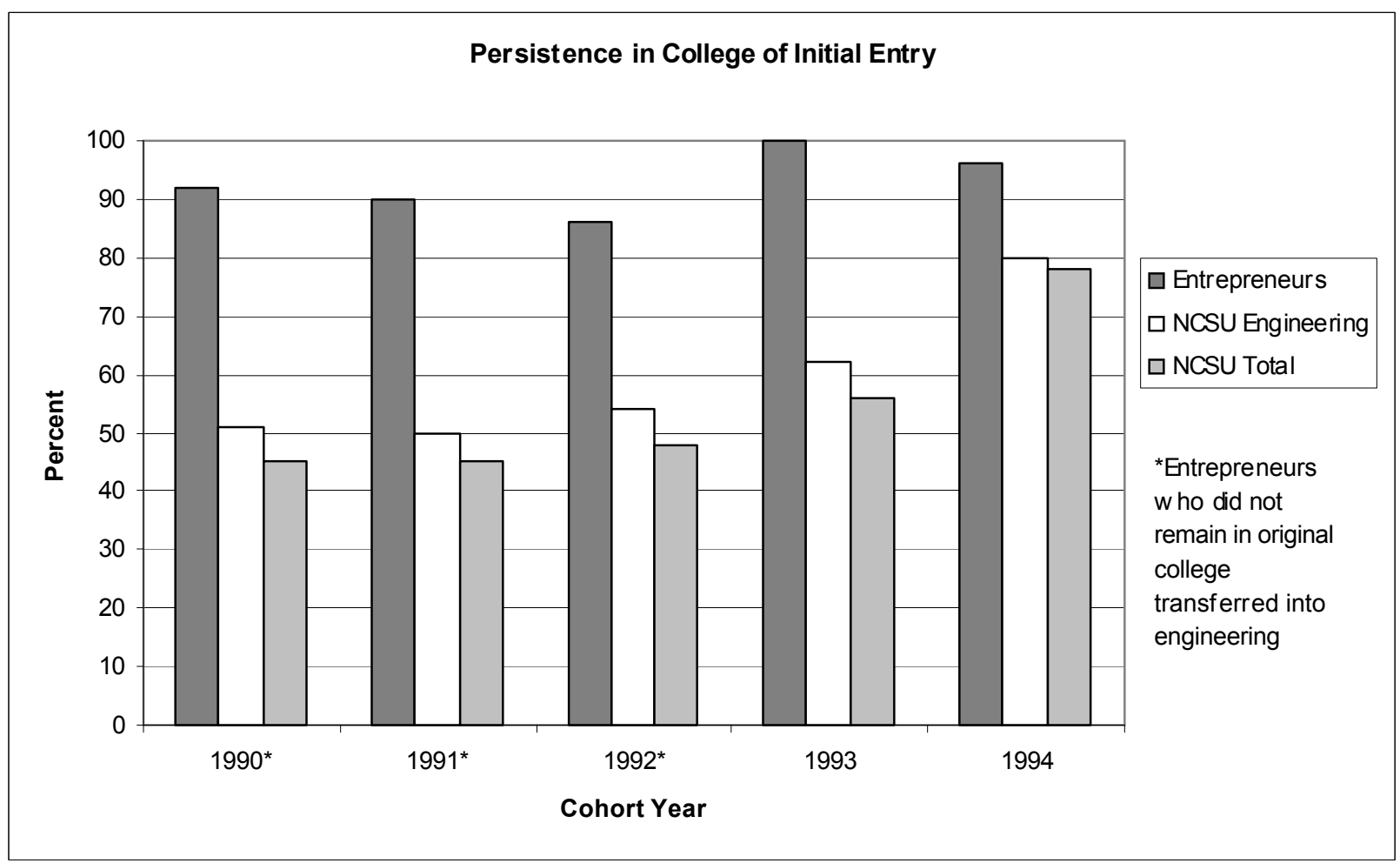

Figure 2. Persistence in College of Entry by Entering Cohort (Earlier Study)

Proceedings of the 2003 American Society for Engineering Education Annual Conference \& Exposition Copyright (C) 2003, American Society for Engineering Education 
Most students chose their ECE major because of a general affinity for computers and/or electrical work. Students taking the EEP who changed majors changed into the ECE department from other engineering majors and from PAMS. This is reflected in Figure 3.

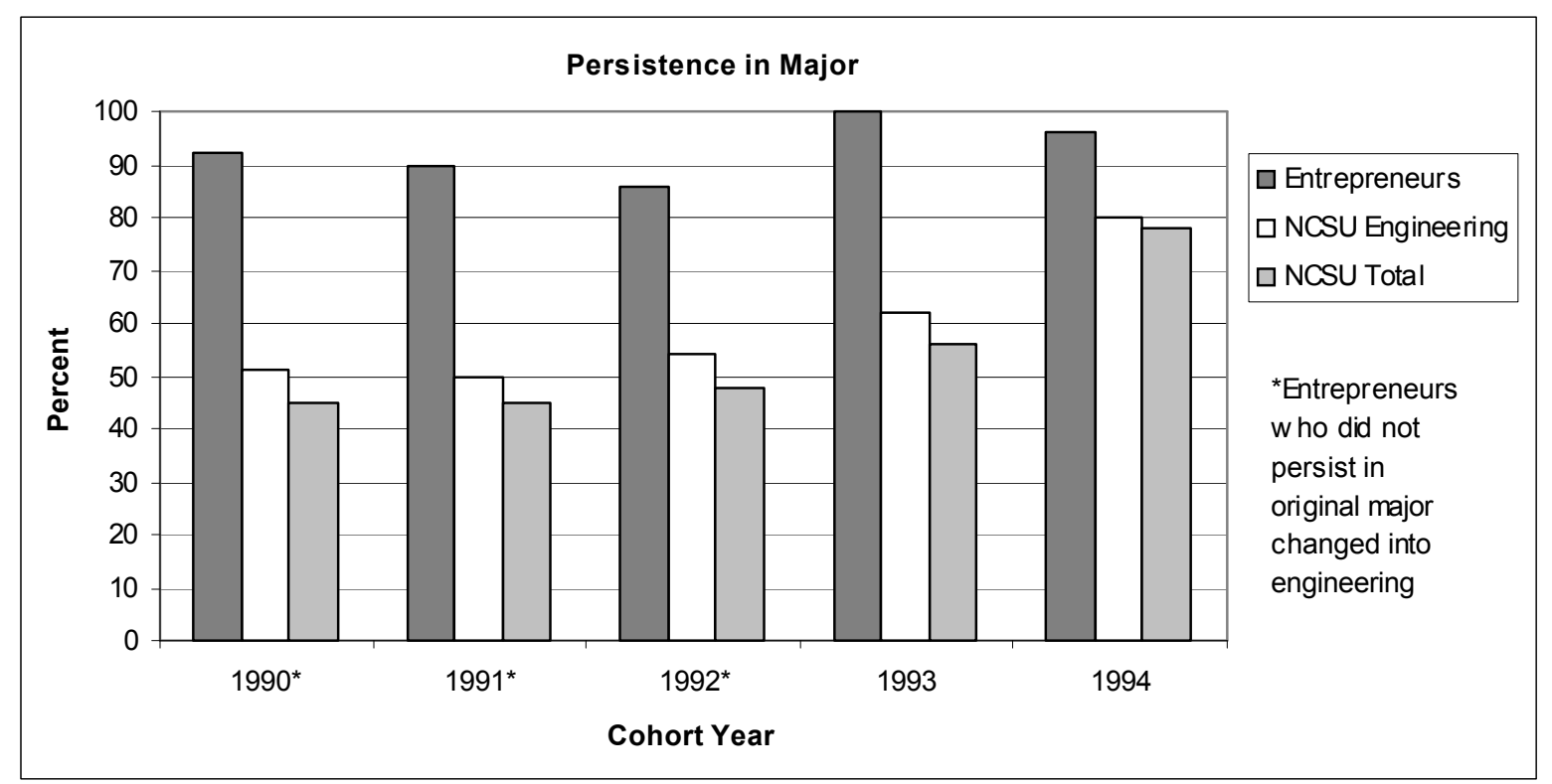

Figure 3. Persistence in College of Entry by Entering Cohort (Earlier Study)

Other students who changed majors did so within the ECE department (e.g. from Computer Science to Computer Engineering). In interviews, they said that they tended to like either programming or engineering and changed their majors to reflect their preferences.

Survey results also provided information as to how the EEP met its objectives. Most students responded on their end of course surveys that they felt more confident pursuing an engineering degree than before, as shown in Figure 4. This was especially true of older students who were able to see how their skills could be applied, but most of the younger students were also more confident. 
I am more confident pursuing an engineering degree.

Percent of each class giving response

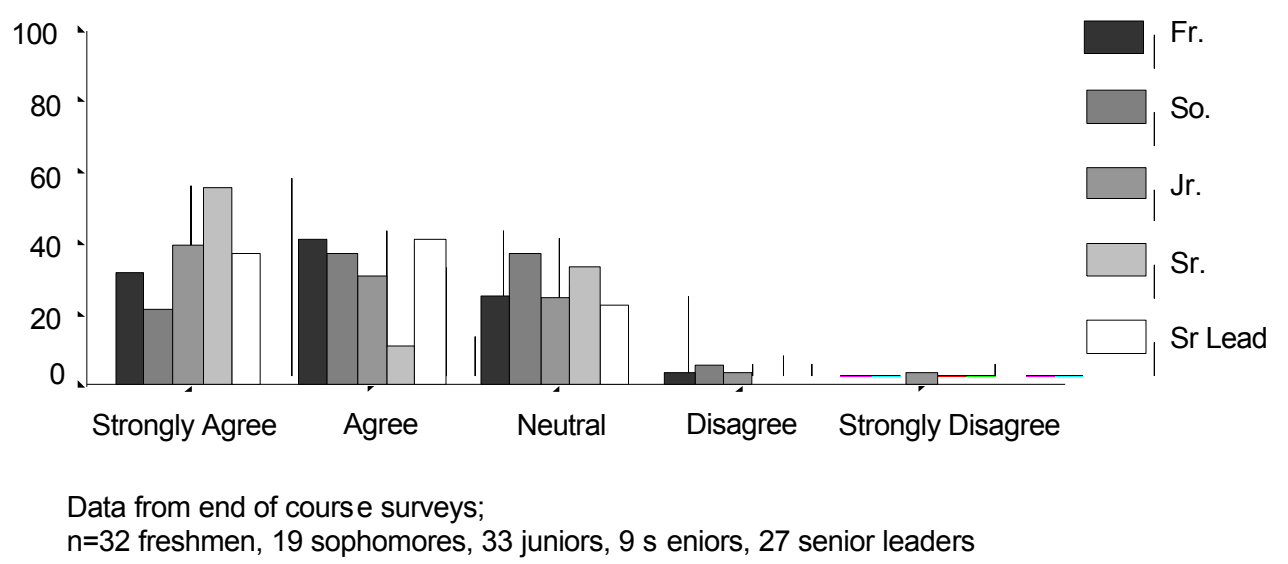

Figure 4. Confidence in Engineering Survey Results (Earlier Study)

Students said that they learned a great deal from the EEP (Figure 5). About 30\% had taken the course more than once. One student had taken it all seven semesters it has been offered. Most of the students said that they had learned a lot from the project experience. As would be expected, seniors all seem to have learned a lot because they had more to put into the program.

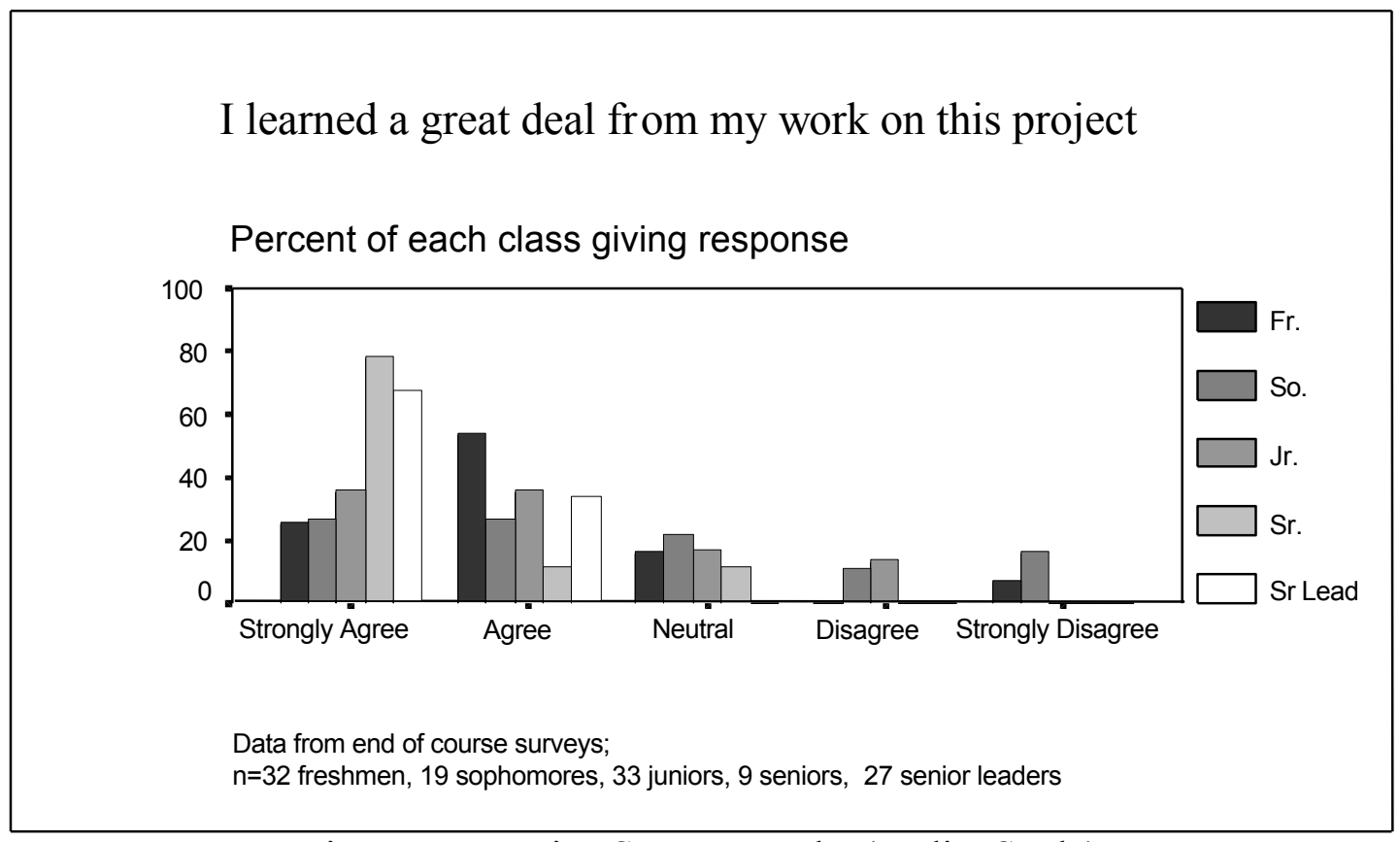

Figure 5. Learning Survey Results (Earlier Study)

Proceedings of the 2003 American Society for Engineering Education Annual Conference \& Exposition Copyright $\left({ }^{\circ} 2003\right.$, American Society for Engineering Education 
With regard to improving the quality of the engineering design experience, seniors who participated in the EEP did not appear to have a significantly different experience from other capstone design students. However, those interviewed agreed that this experience was the best design experience they had in their academic careers because it was the most practical. The multisemester nature of the course was appealing to many students. Two-thirds (14/21) of the underclassmen surveyed said that they would sign up for the course again. Only two students said that they would not sign up again because of a bad experience. In practice, about $25 \%$ of students take the course for multiple semesters. This is most likely due to the fact that underclass students must take the course on an overload basis (i.e., the credit doesn't count toward any requirements) and students find that they have scheduling conflicts.

Teamwork and leadership skills did seem to improve for the students (Figures 6 and 7). Seventyeight percent of the students overall felt that their teamwork skills improved, including $93 \%$ of the senior leaders. All of the senior leaders felt that they were effective leaders although only $80 \%$ of the team participants agreed. On the basis of this disparity, it was recommended that leadership training be provided to help make everyone's experience as positive as possible. The faculty advisors observed the improvement in teamwork and leadership skills throughout the semester and felt that those senior leaders who had participated in the Program earlier were the most effective. Students who had subsequent work experience (through co-ops, internships, or fulltime) found that the leadership and teamwork skills that they learned in the Program were extremely valuable and transferable to their jobs.

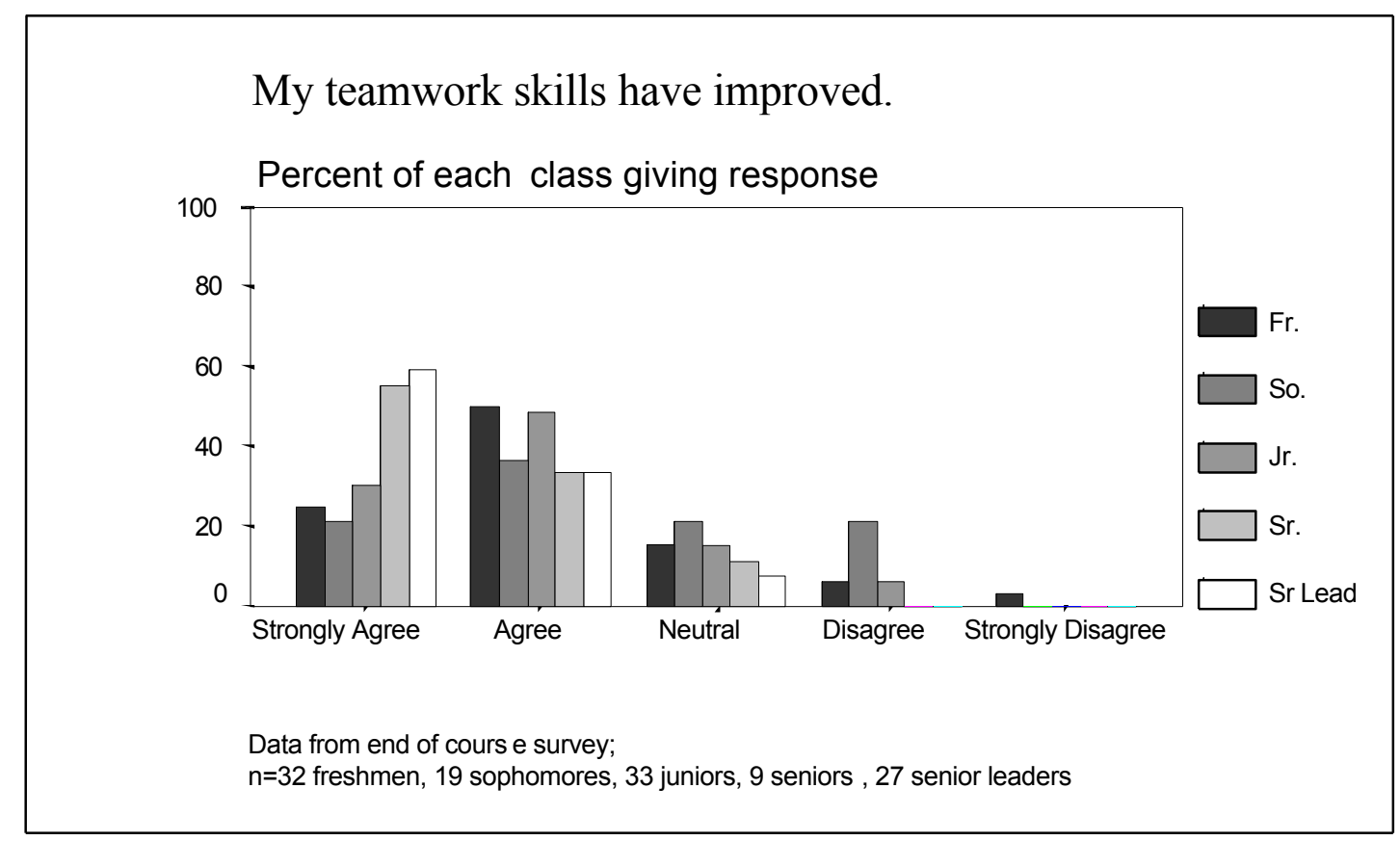

Figure 6. Teamwork Skills Survey Results (Earlier Study) 


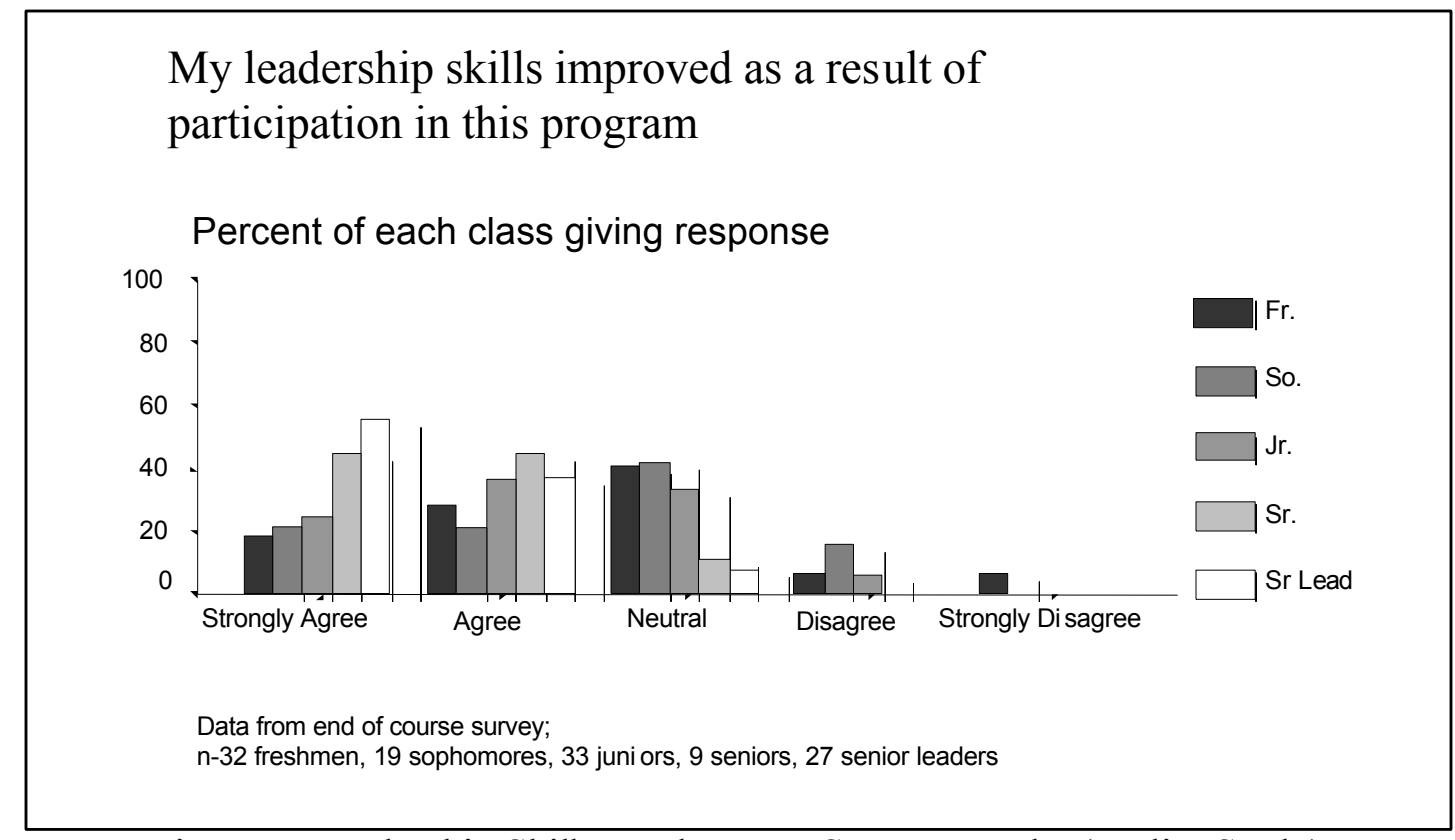

Figure 7. Leadership Skill Development Survey Results (Earlier Study)

Students generally found application to the real world (Figure 8). Those who had worked in coops or internships felt more confident in their abilities to lead and work in teams. Although few students go to work immediately after graduation for a small company (or start one themselves), the skills that they learned are valuable in large companies as well. Industry sponsors, such as IBM, have organized into units where entrepreneurship is encouraged. Students learned about small company dynamics through their teams and the seminar series. Eighty-seven percent of students found the seminars interesting and $88 \%$ found them important.

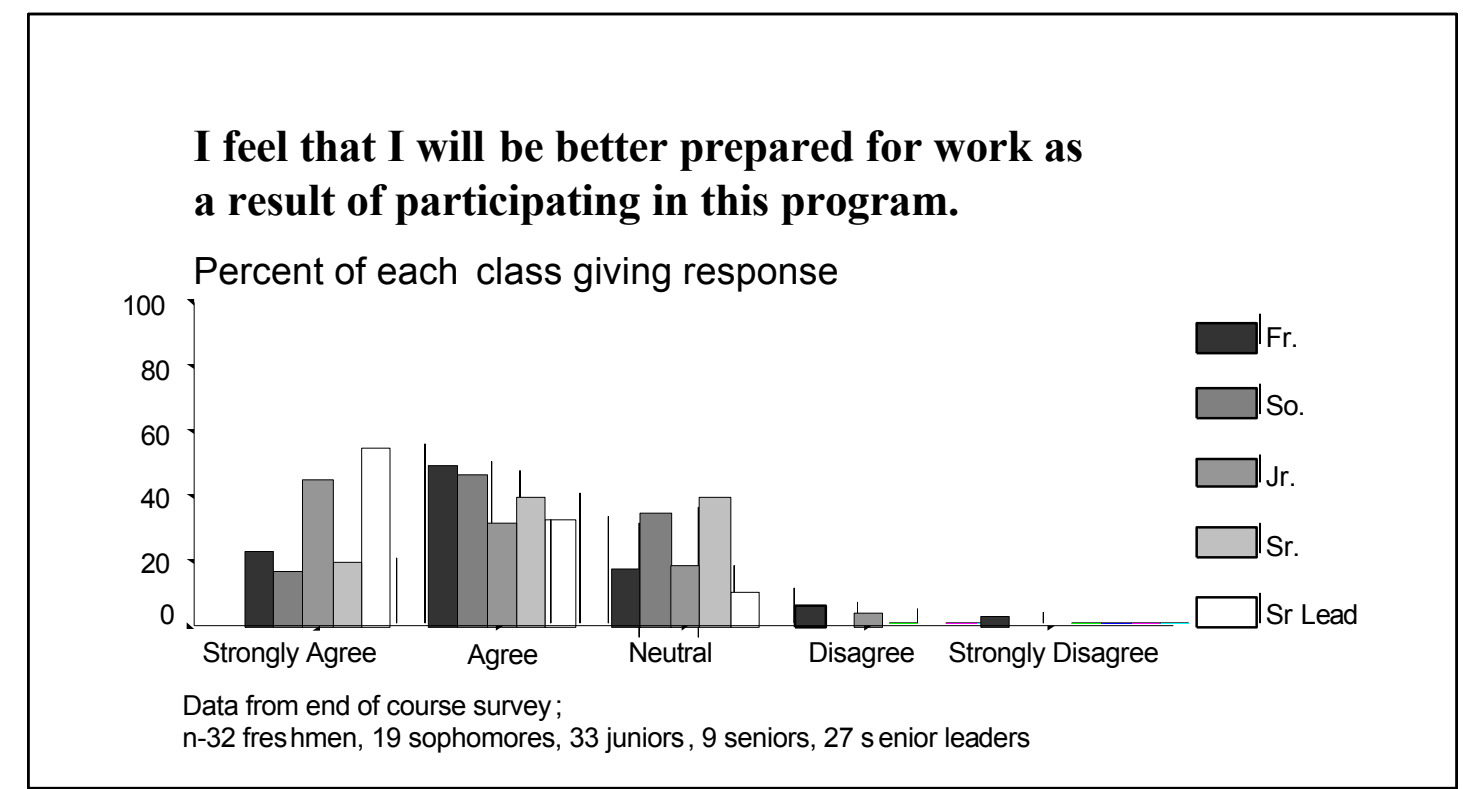

Figure 8. Preparation for Work Survey Results (Earlier Study)

Proceedings of the 2003 American Society for Engineering Education Annual Conference \& Exposition Copyright (C) 2003, American Society for Engineering Education 
This early assessment provided valuable recommendations for improvement of the EEP ${ }^{18}$ and, while not the focus of the assessment, the findings suggested the program had significant value and should be continued.

\section{Longitudinal study protocol}

A longitudinal study of participants in the EEP was initiated following this period of formative assessment. The study aims at evaluating the effectiveness of the program at meeting certain objectives discussed earlier:

1. Retain the interest of students in engineering by involving them in meaningful design experiences early in their academic careers.

2. Improve engineering student quality by involvement in multi-semester design activities.

3. Improve retention by providing senior leaders as role models for underclassmen.

Since these objectives are related to the benefits of participation by lower division (freshman and sophomore) students, only those students are included in this study. The number of lower division participants is shown along with the total number of participants in Table 4. The outcome of (1) and (3) above should be an improvement in the retention in engineering of program participants over a control group with similar characteristics. While the earlier study indicated that the lower division students did recognize the leadership role of (most of) the senior leaders, we lack enough information to prove the causality of that mentoring relationship in any observed improvement in retention in engineering. Thus (1) and (3) are confounded without further qualitative research, and we are therefore assessing the objective, "improve retention by involving students in meaningful design experiences early in their academic careers and by providing senior leaders as role models for underclassmen." Based on objective (2) above, we expected to observe an improvement in the later performance of students, as measured by GPA.

Table 4. Total Course and Lower Division Enrollment in Engineering Entrepreneurs Program

\begin{tabular}{|l|c|c|}
\hline $\begin{array}{l}\text { Entering } \\
\text { semester }\end{array}$ & $\begin{array}{c}\text { Students } \\
\text { in program }\end{array}$ & $\begin{array}{c}\text { Lower } \\
\text { division } \\
\text { students }\end{array}$ \\
\hline Spring 1994 & 44 & 10 \\
\hline Fall 1994 & 52 & 29 \\
\hline Spring 1995 & 56 & 32 \\
\hline Fall 1995 & 21 & 11 \\
\hline Spring 1996 & 27 & 12 \\
\hline Fall 1996 & 36 & 13 \\
\hline Spring 1997 & 24 & 5 \\
\hline Fall 1997 & 7 & 3 \\
\hline Spring 1998 & 32 & 16 \\
\hline Spring 1999 & 25 & 8 \\
\hline
\end{tabular}

Proceedings of the 2003 American Society for Engineering Education Annual Conference \& Exposition Copyright $\left({ }^{\circ} 2003\right.$, American Society for Engineering Education 
While enrollment clearly fluctuates, the Fall 1997 enrollment attracts attention as unusually low. The course was not supposed to have been offered during that semester, but a small group of students were enrolled in it before the section was to be cancelled. A total enrollment for all semesters of 139 is shown in Table 4, but repeat enrollment reduces the number available for study. Table 5 shows the frequency of participation of the 107 students who most commonly enrolled only once in the course in the time period of the study.

Table 5. Frequency of Course Participation for Lower Division Students in Longitudinal Study

\begin{tabular}{l|c|c|c|c|c|c} 
Number of semesters participated & $\mathbf{1}$ & $\mathbf{2}$ & $\mathbf{3}$ & $\mathbf{4}$ & $\mathbf{5}$ & $\mathbf{6}$ \\
\hline Number of students & 87 & 14 & 2 & 3 & 0 & 1
\end{tabular}

Of the 107 lower division students who had taken the EEP in one or more of the semesters listed in Table 4, university data was available for 103 of them. Twelve of these students were transfer students and were deleted from further analysis since their transfer status would confound both of the outcomes under study, leaving 91 students in the population under study.

Using the SUCCEED longitudinal database, ${ }^{19}$ each of the EEP participants was matched with a student who is not in the EEP but who has the same gender, ethnicity, cohort, engineering major, and similar SAT scores. This method helps control for a number of possible biases associated with a course for which students self-select. Student's Grade Point Average, cohort, graduation, and retention data for the experimental group (labeled EEP) and the control group (labeled Non-EEP) were also obtained from the SUCCEED longitudinal database. Retention figures shown in Table 6 include students graduated or still enrolled in an engineering discipline as of Fall 2000. GPA data for participant/non-participant pairs is shown in Table 7 and summarized in Figure 9.

Table 6: Retention data for matched pairs of EEP and non-EEP students

\begin{tabular}{|l|c|c|c|}
\hline & Non-EEP retained & Non-EEP not retained & \multicolumn{1}{l|}{ Total } \\
\hline EEP retained & $\mathrm{n}_{11}=34$ & $\mathrm{n}_{12}=30$ & $\mathrm{n}_{1_{+}}=\mathbf{6 4}$ \\
\hline EEP not retained & $\mathrm{n}_{21}=12$ & $\mathrm{n}_{22}=15$ & $\mathrm{n}_{2+}=\mathbf{2 7}$ \\
\hline Total & $\mathrm{n}_{+1}=\mathbf{4 6}$ & $\mathrm{n}_{+2}=\mathbf{4 5}$ & $\mathrm{n}_{++}=\mathbf{9 1}$ \\
\hline
\end{tabular}




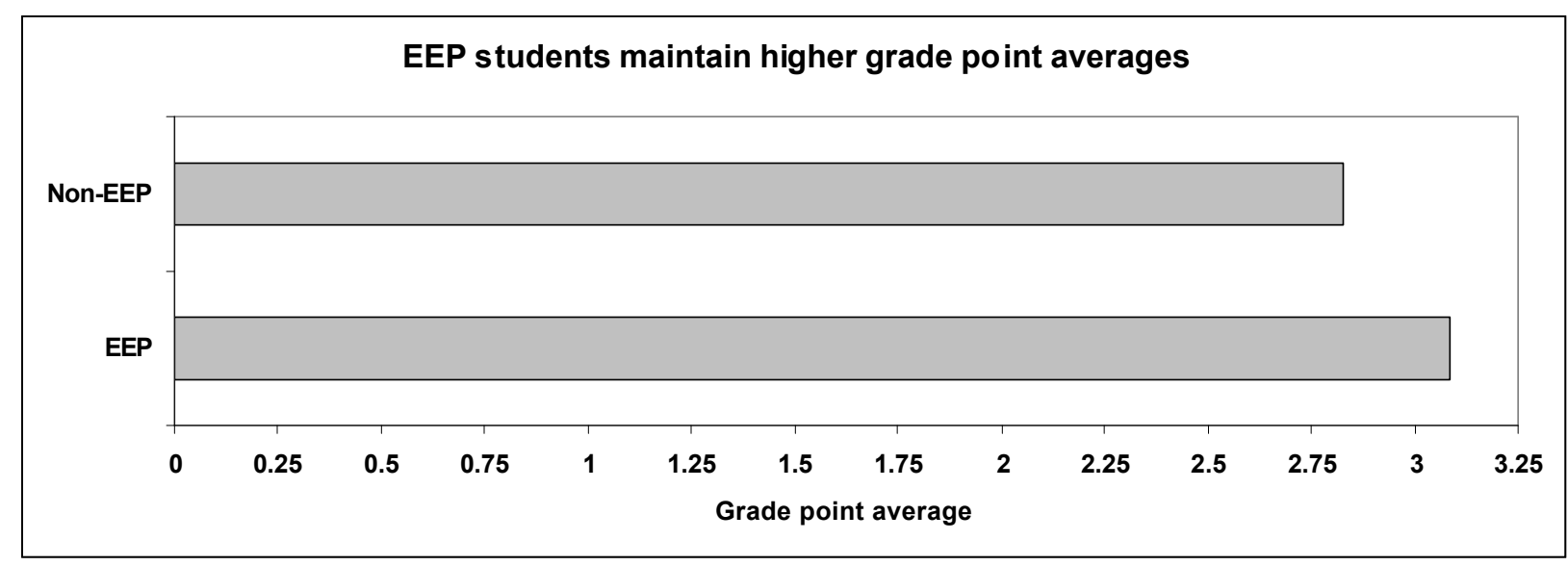

Figure 9. Grade point average, EEP participants compared to non-participants.

\section{Analysis of Longitudinal Retention Data}

Table 6 cross-classifies NCSU engineering students in the study according to whether they participated in the EEP program and whether they were retained. A total of 91 pairs of students were studied, each pair consisting of an EEP participant and a non-participant matched as described above. Of those 91 pairs, 34 pairs showed both EEP participants and non-participants were retained; in 15 pairs, neither participants nor non-participants were retained; in 30 pairs, the participant was retained while the non-participant was not retained; and in 12 pairs, the nonparticipant was retained while the participant was not retained. Overall, out of the same number of students, 64 of the EEP group retained while 46 from the Non-EEP group retained.

For such data, we want to study whether a statistically significant association exists between EEP and retention. We seek to answer the question, "are students who participate in the EEP programs more likely than those who do not participate in the program to graduate or to stay in engineering, or is the chance of graduation independent of whether the students are in the EEP program?"

The McNemar Test for matched pairs was used to test for marginal homogeneity for matched binary responses. ${ }^{20}$ The null hypothesis was: $\pi_{1+}=\pi_{+1}$, or the probability of retention is the same for the EEP group and the Non-EEP group. The alternative hypothesis was: $\pi_{1+} \pi_{+1}$, or the probability of retention for EEP group was higher than that for Non-EEP group. The McNemar Test statistic provides very strong evidence that the EEP group's retention rate was significantly higher than for the non-EEP group $\left(\chi^{2}=7.71, \mathrm{df}=1, \mathrm{p}=.005\right) .{ }^{21}$

While the McNemar Test indicates that the probability of retention was higher for the EEP group than for the non-EEP group, the test does not tell us by how much the probability of retention was higher. To answer this question, we estimated the population difference in proportion by using sample difference in proportion and constructing a 95\% confidence interval on the difference. A confidence interval for the difference of proportions is more informative than a 
hypothesis test. Using another form from Agresti, we can claim that we are $95 \%$ confident that the true difference in proportion of retention between EEP group and Non-EEP group is between $6.5 \%$ and $33.1 \%$. Thus we are $95 \%$ confident that EEP participants are at least $6.5 \%$ more likely to be retained in engineering, and may be as much as $33.1 \%$ more likely to be retained.

\section{Analysis of Longitudinal GPA Data}

Student Grade Point Averages from were obtained for students who were either graduated or still enrolled in an engineering discipline. In cases where one or both of a pair of students are missing a value of GPA (such as if either of the pair left the university entirely), the pair was eliminated from the GPA study. As a result of this constraint, sixty pairs of GPA were available for the GPA study. Since we have already established that EEP participants are retained in engineering at a higher rate, a potential bias is introduced by comparing the GPAs of EEP participants who are retained in engineering to the GPAs of non-EEP participants who have left engineering. Since previous work by Astin has established the direction of this bias - that majoring in engineering has a negative impact on GPA - we can conclude that this bias would tend to make the GPA of the non-EEP group higher. A larger percentage of non-EEP students are no longer subject to the expected reduction in GPA, so if a significant GPA difference is observed, this bias is not of great concern.

The research question in the case of the GPA study was, "Is the mean GPA of the EEP students the same as that of their Non-EEP counterparts?" The alternative hypothesis was: "Is the EEP group's mean GPA higher than non-EEP group's?" The t-test for dependent samples was used to test the hypothesis. The mean GPA for the EEP group was 3.08 with standard deviation .06 . The mean GPA for the Non-EEP group was 2.83 with standard deviation .09. The difference in sample means was 0.26 , and the value of the t-statistic was 1.99 . The one-tailed critical value for $\alpha=0.05$ and $\mathrm{df}=59$ is $t_{\text {critical, }, 05,59}=1.67$, so we find $\mathrm{p}<.05$, and the result is significant. Therefore, we have enough evidence to conclude that the mean GPA for the EEP group was higher than the non-EEP group, in spite of the bias that might tend to obscure this effect. In light of the findings of Astin, this suggests that EEP participation is particularly valuable for improving performance.

\section{Career paths of program participants}

While there has been no formal effort to track the careers of all the graduates who have participated in the EEP, there is anecdotal information on its impact on former students and their career paths. Some students have reported that their experience in the EEP influenced their initial job decisions upon graduation, some starting lifestyle businesses, such as freelance consulting. One has returned to the EEP as a seminar speaker to tell students about his experiences. A number of students have reported that while they have not started companies, the EEP experience has had a significant effect on their careers. One student, who joined IBM upon graduation and later moved to Cisco Systems, indicated that the EEP had defined his entire career. He credited the EEP experience for his understanding of the linkages between technology and business, and his ability to lead teams, both of which he said were critical factors in his advancement with both

Proceedings of the 2003 American Society for Engineering Education Annual Conference \& Exposition Copyright (C) 2003, American Society for Engineering Education 
companies. Others have cited people skills and communication skills developed in the EEP as major contributors to their career advancement. One recently reported that the experience working with her EEP team gave her a level of confidence that allowed her to pursue higher career aspirations than she had previously thought possible. She states: "I honestly feel that without my experience in the Entrepreneurs class, I would not have been able to take the path that I did." Another former student, who is now an Assistant Professor of Mechanical Engineering at SMU, credits the EEP with influencing his decision to pursue an academic career. He cites the entrepreneurial nature of academic research as a factor in his career path decision.

\section{Other measures of the success of the Engineering Entrepreneurs Program}

The Engineering Entrepreneurs Program is successful by other more qualitative measures as well. A series of six videotapes based on the program were produced and are available from IEEE. The video series comes with a supporting information booklet, and has sold copies internationally. ${ }^{22} \mathrm{~A}$ former Engineering Entrepreneurs participant endowed the program with a gift of $\$ 500,000{ }^{23}$ Donald J. Barnes, a 1995 NC State computer engineering alumnus retired early from his first entrepreneurial venture as a 27-year-old millionaire. In presenting the gift to the college, Barnes credited the Engineering Entrepreneurs Program as the key to his success. In addition to the monetary support, the graduate planned to contribute to the program as an advisor and a lecturer. The program has also received considerable attention from the media - it has been featured in the Electronic Engineering Times, ${ }^{24}$ the Triangle Business Journal, ${ }^{25}$ the ASEE Prism, ${ }^{26}$ and National Public Radio's “Morning Edition"- an audio transcript is available. ${ }^{27}$

\section{Conclusions}

The model of the Engineering Entrepreneurs Program is one that we feel can be implemented in any engineering program. It lends itself well to multidisciplinary teams, although those have not yet been formally implemented at NC State. The program has been successful at promoting retention and higher grades in engineering and in developing teamwork and leadership skills among the participants. Students who participate for multiple semesters seem to get the most benefit. They learn teamwork skills and leadership skills and have the opportunity to continuously apply them as they develop more technical skills.

\section{Acknowledgments}

This material is based upon work supported by the National Science Foundation's Southeastern University and College Coalition for Engineering Education (SUCCEED), under cooperative agreement NSF EEC-9727411. All records of student performance were taken from the SUCCEED Longitudinal Database. We are also grateful to Lewis Carson, Associate Director of Institutional Research at North Carolina State University, for his efforts in the initial design and implementation of that database.

\section{Author Biographies}

Proceedings of the 2003 American Society for Engineering Education Annual Conference \& Exposition Copyright (C) 2003, American Society for Engineering Education 
MATTHEW W. OHLAND

is an Assistant Professor in Clemson University's General Engineering program and is the President of Tau Beta $\mathrm{Pi}$, the national engineering honor society. He received his Ph.D. in Civil Engineering with a minor in Education from the University of Florida in 1996. Previously, he served as Assistant Director of the NSF-sponsored SUCCEED Engineering Education Coalition. His research is primarily in freshman programs and educational assessment.

\section{GUILI ZHANG}

is a Ph.D. candidate in Educational Research and Statistics at the University of Florida. She received a B.A. in British and American Language and Literature at Shandong University, China, and a M.Ed. in English Education at Georgia Southern. She has published extensively and won numerous awards in the area of educational research in China. She studies applied quantitative research, categorical data analysis, and structural equation modeling.

\section{CATHERINE E. BRAWNER}

is president of Research Triangle Educational Consultants. She specializes in educational program evaluation in the areas of engineering education, distance education, and technology use in the classroom. She received her PhD in Educational Research and Policy Analysis from North Carolina State University and has been the principal evaluator for the SUCCEED Coalition and the UNC system's Preparing Tomorrow's Teachers to Use Technology program.

\section{THOMAS K. MILLER III}

is a Professor of Electrical and Computer Engineering at North Carolina State University and Director of the Engineering Entrepreneurs Program, which he founded in 1993. He received the PhD in Biomedical Engin eering and Mathematics from the University of North Carolina in 1982, and is a member of the Academy of Outstanding Teachers at NC State.

\section{References}

\footnotetext{
${ }^{1}$ Cohen, A. M., Brawer, F. B., \& Kozeracki, C. A. (1998). Jumpstart I summary report. Los Angeles, CA: Center for the Study of Community Colleges. (ERIC Document Reproduction Service No. ED 416198)

${ }^{2}$ Narayan, R. (2002, June). An engineering entrepreneurship course for ChE seniors. Symposium conducted at the American Society for Engineering Education Annual Conference and Exposition.

${ }^{3}$ Carlson, L. E., \& Sullivan, J. F. (2002, June). Exploring entrepreneurship through product development: A handson approach. Symposium conducted at the American Society for Engineering Education Annual Conference and Exposition.

${ }^{4}$ Creed, C. J., Suuberg, E. M., \& Crawford, G. P. (2002, April). Engineering entrepreneurship: An example of a paradigm shift in engineering education. Journal of Engineering Education, 185-195, p. 185.

${ }_{5}^{5}$ Mason, T. W., \& Western, A. B. (2001, June). The engineer as entrepreneur: Education for the $21^{\text {st }}$ century at Rose-Hulman Institute of Technology. Symposium conducted at the American Society for Engineering Education Annual Conference and Exposition.

${ }^{6}$ Carlson, L. E., \& Sullivan, J. F. (2002, June). Exploring entrepreneurship through product development: A handson approach. Symposium conducted at the American Society for Engineering Education Annual Conference and Exposition.

${ }^{7}$ Keating, D. A., Stanford, T. G., Dunlap, D. D., Bennett, R. J., Mendelson, M. I., Sebastian, D. H., \& Tricamo, S. J. (2002, June). Lifelong learning for innovation and leadership in engineering. Symposium conducted at the American Society for Engineering Education Annual Conference and Exposition.

${ }^{8}$ Tooley, Melissa S., and Kevin D. Hall, "Using A Capstone Design Course to Facilitate ABET 2000 Program Outcomes," Proc. Amer. Soc. Eng. Ed. 1999, Session 1625, 1999.

${ }^{9}$ Devgan, Satinderpaul Singh, M. S. Zein-Sabatto, M. Bodruzzaman, and Decatur B. Rogers, "Meeting ABET EC

2000 through Student Research Participation," Proc. Frontiers in Education 1999, Session 12a9, 1999.

Proceedings of the 2003 American Society for Engineering Education Annual Conference \& Exposition Copyright (C) 2003, American Society for Engineering Education
} 
${ }^{10}$ Ohland, M.W., T.J. Anderson, D.F. Ollis, D.H. Phillips, K.H. Murray, and J. Hebrank, "Nine Approaches to Including Multidisciplinary Design in the Curriculum," International Conference on Engineering Education 1999, published in proceedings on CD-ROM, paper 340, 1999.

${ }^{11}$ Carlson, L. E., \& Sullivan, J. F. (2002, June). Exploring entrepreneurship through product development: A hands-on approach. Symposium conducted at the American Society for Engineering Education Annual Conference and Exposition.

${ }^{12} \mathrm{http}: / /$ www.nciia.org/who/index.html

${ }^{13}$ Kingon, A. I., Markham, S., Thomas, R., \& Debo, R. (2002, June). Teaching high-tech entrepreneurship: Does it differ from teaching entrepreneurship? (And does it matter?). Symposium conducted at the American Society for Engineering Education Annual Conference and Exposition.

${ }^{14}$ Miller III, Thomas K., "Engineering Entrepreneurs: Crafting Technology Leaders for the 21st Century," Proc. IEEE, 88(6), 864-867, June 2000.

${ }^{15}$ Miller III, Thomas K., and James J. Brickley, The Engineering Entrepreneurs Program at North Carolina State University, http://www.engr.ncsu.edu/eep.

${ }^{16}$ Southeastern University and College Coalition for Engineering Education website, http://www.succeednow.org/

${ }^{17}$ Miller III, Thomas K., "Engineering Entrepreneurs: Crafting Technology Leaders for the 21st Century," Proc. IEEE, 88(6), 864-867, June 2000.

${ }^{18}$ Brawner, Catherine E., "The Entrepreneurs Program at North Carolina State University," submitted to SUCCEED, December 18, 1995.

${ }^{19}$ Ohland, M.W., and T.J. Anderson, "Studying the Contribution of Programs at Eight Engineering Colleges toward Student Success," Proc. Frontiers in Education (FIE) 1999, San Juan, Puerto Rico, November 10-14, 1999. ${ }^{20}$ Agresti, A., An Introduction to Categorical Data Analysis, John Wiley \& Sons, Inc., New York, 1996, p. 228.

${ }^{21}$ Agresti, 1996, p. 228.

${ }^{22}$ Daugherty, Scott R., Richard Holcomb, James P. Poitras, Mark Friedman, and Thomas K. Miller, Entrepreneurial Skills Seminar Series, Six videos (NTSC), IEEE Foundation Product No. EV5517-TBR, ISBN 07803-4576-2, 1997.

${ }^{23} \mathrm{http}: / /$ www.engr.ncsu.edu/news/gifts.arch.00.summer.html

${ }^{24}$ Bellinger, Robert, "Class sparks entrepreneurial spirit in CS/EEs," Electronic Engineering Times, February 12, 1996.

${ }^{25}$ Strow, David, "NCSU produces pack of tech entrepreneurs," Triangle Business Journal, April 10, 1998.

${ }^{26}$ Fitzgerald, Nancy, "Entrepreneur Trainers," ASEE Prism, January 1997, p. 19.

${ }^{27}$ National Public Radio's "Morning Edition," Feb 23, 2000,

http://www.npr.org/ramfiles/me/20000223.me.06.rmm

Proceedings of the 2003 American Society for Engineering Education Annual Conference \& Exposition Copyright $\left({ }^{\circ} 2003\right.$, American Society for Engineering Education 